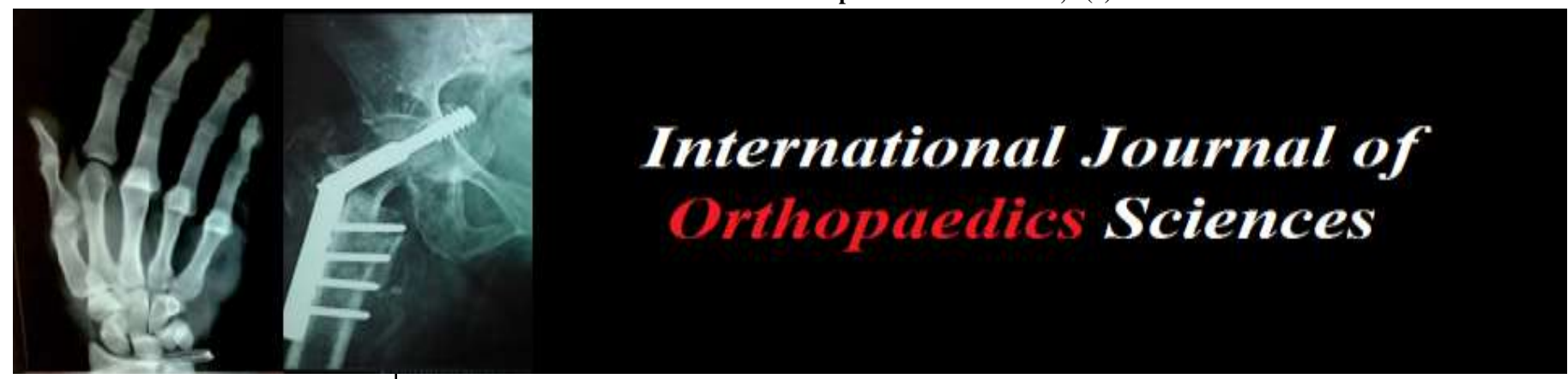

E-ISSN: 2395-1958

P-ISSN: 2706-6630

IJOS 2020; 6(4): 905-908

(C) 2020 IJOS

www.orthopaper.com

Received: 07-09-2020

Accepted: 16-10-2020

Dr. Bharat Swaroop Mittal Resident, Department of Orthopedics, Dr. DY Patil Hospital and Research Centre, Pune, Maharashtra, India

Dr. Abhijeet Shroff

Associate Professor, Department of Orthopedics, Dr. DY Patil

Hospital and Research Centre,

Pune, Maharashtra, India

Dr. Jaiman Sharma

Resident, Department of Orthopedics, Dr. DY Patil

Hospital and Research Centre, Pune, Maharashtra, India
Corresponding Author: Dr. Bharat Swaroop Mittal Resident, Department of Orthopedics, Dr. DY Patil Hospital and Research Centre, Pune, Maharashtra, India

\section{Efficacy of percutaneous release of trigger finger}

\author{
Dr. Bharat Swaroop Mittal, Dr. Abhijeet Shroff and Dr. Jaiman Sharma
}

DOI: https://doi.org/10.22271/ortho.2020.v6.i4m.2439

\section{Abstract}

Trigger finger is one of the most common cause of pain and disability of the hand. This condition results in painful catching or popping of the involved flexor tendon as the patient flexes and extends the digit. This study aimed to test the efficiency of percutaneous release in the treatment of Trigger Finger in 100 patients. Percutaneous Release of A1 pulley of the affected digit was performed using $18 \mathrm{G}$ needle under Local Anaesthesia in the Out Patient Department. Results were graded using Quinnel's criteria as excellent if there was no pain after the procedure, good if pain occurred with heavy use or poor if there was no reduction in pain. Excellent result was achieved in 83 patients while good results achieved in 13 patients who were satisfied and were able to return to their work the next day of the procedure. In 4 patients the procedure failed to relieve the symptoms and there was some degree of residual triggering and pain left. At 1 week follow up only 9 patients had some degree of pain and stiffness which had completely resolved on taking medication and there were no complaints at 3 months follow up. Percutaneous release is a safe, effective and cheap procedure, providing immediate relief from symptoms in the treatment of trigger finger which is well tolerated and has a low rate of complications when done by an experienced Orthopaedic surgeon.

Keywords: Trigger finger, percutaneous release, A1 pulley, tenosynovitis, quinnel's criteria

\section{Introduction}

Trigger finger or Stenosing Tenosynovitis is a common condition resulting in painful catching or locking involving the flexor tendon when the patient flexes and extends the digit. It contributes to mild to moderate disability of the hand and is believed to occur due to a variance in the thickness of the flexor tendon as well as its retinacular sheath which may occur due to the flexor sheath thickening ${ }^{[1,2,3,4]}$.

Occasionally there is locking of the digit in a flexed position which requires passively manipulating the digit to achieve full extension. Secondary contractures may develop over a period of time at the proximal interphalangeal joint due to reluctance of the patient to mobilise the digit.

Various treatment modalities have been advocated. Conservative methods include analgesics and splintage which showed a $92.9 \%$ improvement in triggering ${ }^{[5,6]} .53 .6 \%$ had complete resolution of triggering and $39.3 \%$ had partial resolution on wearing a custom made thermoplastic splint for 6-10 weeks while in $7.1 \%$ triggering had not relieved even after 10 weeks of splint usage ${ }^{[5,6]}$.

Interventional modalities consist of corticosteroid injections and percutaneous release [7,28]. Study by Newport et al., showed a $77 \%$ resolution rate in the treatment of trigger finger with $49 \%$ requiring a single injection, $23 \%$ requiring 2 injections and 5\% requiring 3 injections ${ }^{[28]}$. Another study had only a $47 \%$ success rate with steroid injection alone [23].

Open surgery is reserved for patients who do not respond to multiple attempts at the above mentioned modalities. Patient satisfaction and early functional recovery has been reported with percutaneous release ${ }^{[8]}$.

In this study, we used an 18 gauge needle to release of trigger finger percutaneously, and conducted 3 month follow up of the patients recording their outcomes in terms of range of movement, pain and patient satisfaction.

\section{Materials and Methods}

Our study is a prospective observational study that was conducted at a tertiary care hospital in Pune, Maharashtra for a duration of 2.5 years from June 2018 to March 2021. 
In this study 100 patients were included, with all patients ( $>15$ years of age) presenting with trigger finger (grade II-IV), diagnosed using Quinnel's criteria (Fig. 1) on the basis of clinical symptoms such as uneven movement at the metacarpophalyngeal joint, locking which was actively or passively correctable, and pain were included in the study.

\begin{tabular}{|c|c|c|}
\hline \multicolumn{3}{|c|}{ QUINNEL'S CRITERLA } \\
\hline Grade & \multicolumn{2}{|c|}{ Clinical findings } \\
\hline 1 & \multicolumn{2}{|c|}{ Normal movement, no pain } \\
\hline 11 & \multicolumn{2}{|c|}{ Normal movement, occasional pain } \\
\hline iII & \multicolumn{2}{|r|}{ Uneven movement } \\
\hline IV & \multicolumn{2}{|c|}{ Intermittent locking, actively correctable } \\
\hline v & \multicolumn{2}{|c|}{ Locking, only passively correctable } \\
\hline \multicolumn{3}{|c|}{ 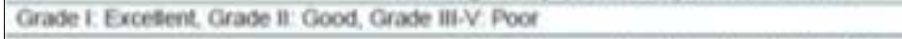 } \\
\hline Pating & Pain & Activity and patient satisfaction \\
\hline Excellent & No pain & $\begin{array}{l}\text { Returned to work or activity } \\
\text { patient satisfied }\end{array}$ \\
\hline Good & $\begin{array}{l}\text { Pain only with } \\
\text { heavy use }\end{array}$ & $\begin{array}{l}\text { Retumed to work or activity } \\
\text { patient satisfied }\end{array}$ \\
\hline Poor & Pain unchanged & Patient dissatisfied \\
\hline
\end{tabular}

Fig 1: Quinnel's criteria used for classifying trigger finger based on movement abnormality, pain and locking. It is also used to classify the outcome of percutaneous release

Exclusion criteria included Trigger finger grade I and V, patient age less than 15 years, symptoms of less than 1 month duration, patients on anti-coagulants, any acute history of trauma and lastly pregnancy.

We took a formal written consent from the patients before we included them in the study.

We assessed patient satisfaction through direct questioning using the Gilerbert's questionnaire, the Quinnel's criteria and analyzing pain on VAS scale. Antibiotics were not prescribed prophylactically.

We performed this procedure using local anesthesia comprising of a $2 \%$ solution of Lidocaine, infiltrated using an 18 gauge needle just distal to the distal palmar crease of the affected digit on the volar surface $[9,10]$. We hyper-extended the finger at the metacarpophalangeal joint which brings the flexor tendon sheath to lie directly under skin and causes displacement of the digital neurovascular bundles to either side ${ }^{[10,11]}$. Then, the A1 pulley over the metacarpophalangeal joint was released utilizing the 18 gauge needle with a proximal to distal stroking motion keeping the bevel of the needle aligned according to the long axis of the finger. Multiple sweeps were taken and release of the A1 pulley was assessed based on a loss of gritty sensation and immediate relief of pain and catching. Sutures were not taken however a small non-restrictive dressing was applied over the site of needle prick.

In the post-operative period active hand and finger movements were assessed and encouraged.

Periodic follow ups in the clinic were conducted at after 7 days and 3 months post operatively to assess pain, triggering and range of motion.

\section{Results}

Out of the 100 patients in this study, 61 were male and 39 female with their age ranging from $38-61$ years and a mean age of 51.36 years. 38 of those patients were diabetic and 2 were hypertensive.

In 58 of the patients the right hand was affected while the left was involved in 32 patients. The ring finger was the most common digit involved, 87 times while the middle finger was affected in 13 patient. No other finger was involved in this study.

Locking was the most common complaint which was seen in all 100 patients while 12 patients also had pain. 90 of the patients were diagnosed with Quinnel's criteria grade IV, 8 patients with grade III and 2 with grade II (Table 1).
Table 1: Grading of symptoms of trigger finger based on Quinnel's criteria

\begin{tabular}{|c|c|}
\hline Quinnel's criteria & N (\%) \\
\hline Grade II & 2 \\
\hline Grade III & 8 \\
\hline Grade IV & 90 \\
\hline
\end{tabular}

Patients had suffered from their complaints for a duration ranging from $2-6$ months and a mean duration of 3.01 months. The procedure lasted for a range of $2-11$ minutes averaging 3.47 minutes (Fig 1).

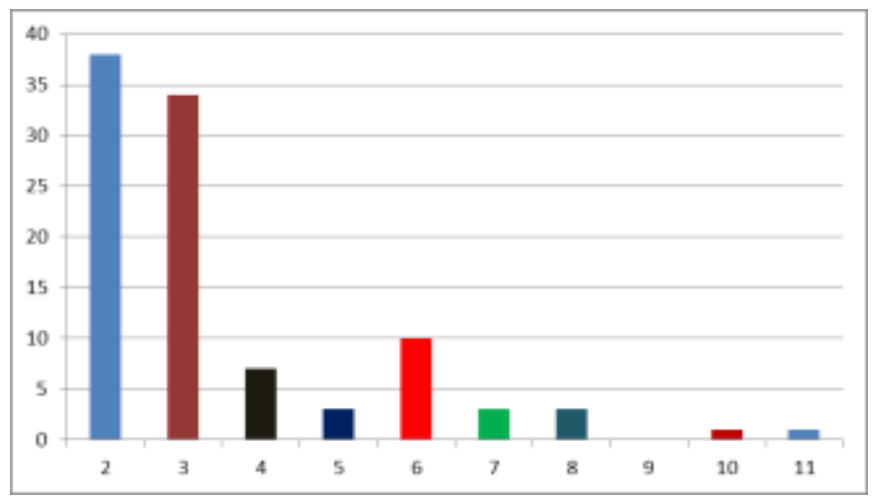

Fig 1: Duration of surgery in minutes

Of the total 100 patients included in this study, 83 patients had an excellent result, 13 had a good result and the remaining 4 had a poor result (Fig 2).

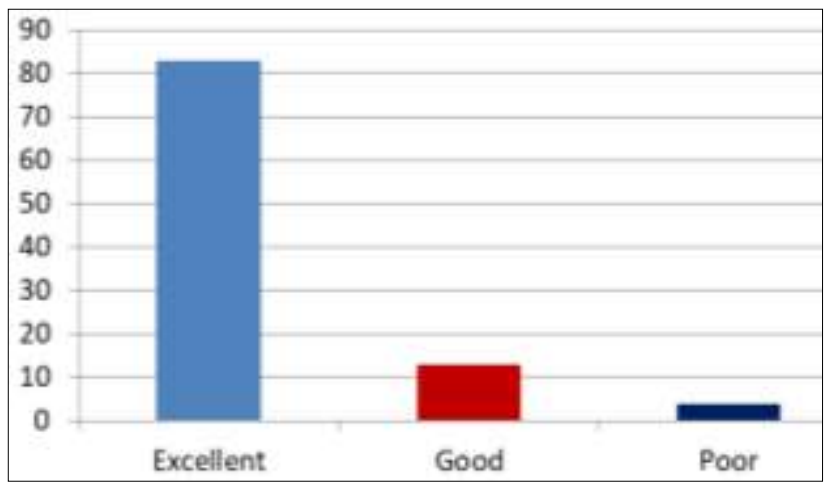

Fig 2: Outcome of surgery 
Out of the 90 patients with Grade IV Trigger finger, 75 had an excellent result, 11 had a good result and 4 had a poor result. 6 patients with Grade III Trigger finger had an excellent result, the remaining 2 had a good result and the 2 patients with Grade II Trigger finger, both had an excellent result. (Fig $3)$.

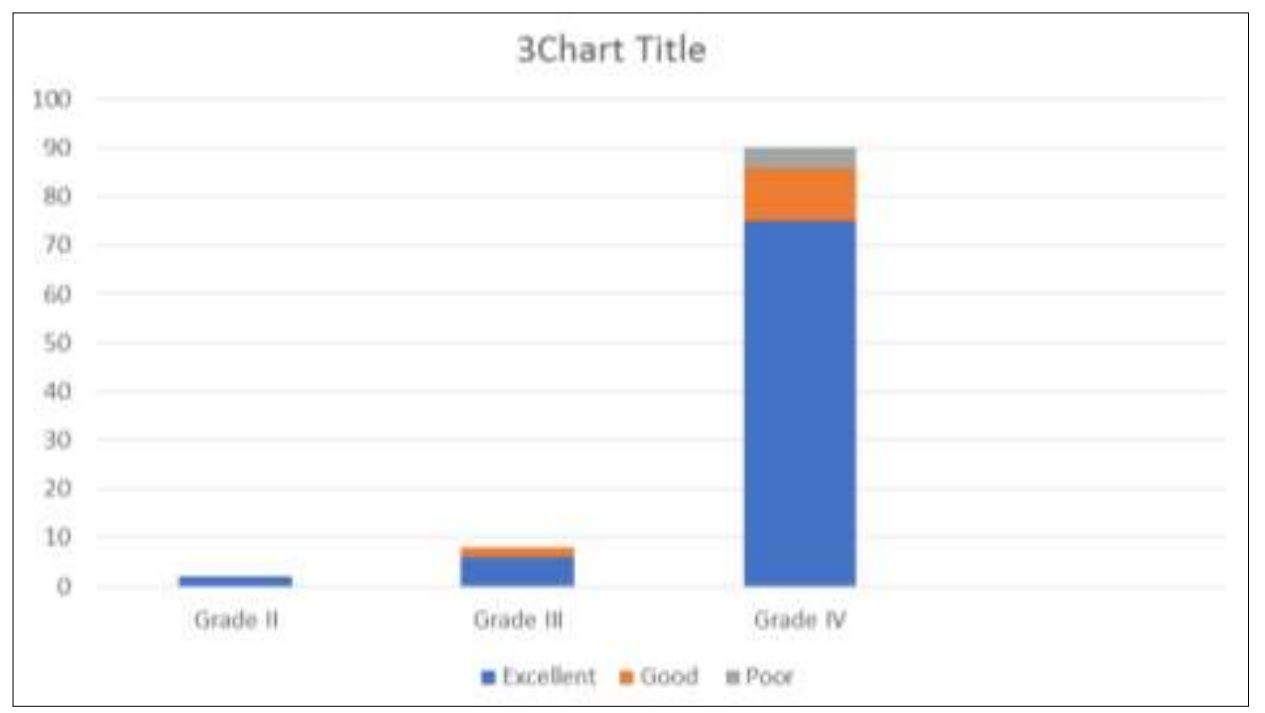

Fig 3: Correlating the various outcomes (Excellent, good and poor) with the pre-procedure grading of trigger finger

Only 12 patients had immediate post procedure stiffness which was mild in 11 patients and moderate in 1 . The other 88 patients did not suffer from any stiffness (Table 2 ).

Table 2: Incidence of post-op stiffness

\begin{tabular}{|c|c|}
\hline Post-op stiffness & Number of patients (\%) \\
\hline Present & 12 \\
\hline Mild & 11 \\
\hline Moderate & 1 \\
\hline Absent & 88 \\
\hline
\end{tabular}

Post procedure the pain lasted for 1-12 days with an average of 4.43 days. On follow up after 1 week only 9 patients had mild pain and stiffness which was relieved on taking medication and after 3 months follow up none of the patients had any complaints (Table 3).

Table 3: Follow up at 1 week

\begin{tabular}{|c|c|}
\hline Follow up at 1 week & Number of patients (\%) \\
\hline Mild pain and stiffness & 9 \\
\hline No complaints & 91 \\
\hline
\end{tabular}

There was no complaint of residual locking from any of the 100 participants of this study.

\section{Discussion}

The etiology of Stenosing Tenosynovitis is still unclear. On the inner surface of the A1 pulley, fibrocartilage metaplasia is found which was implicated to be the cause of the triggering by Sampson ${ }^{[12]}$. Nodule formation of the flexor tendon at the site of constriction may also be a contributing factor ${ }^{[13]}$.

In our study the ring finger was most commonly affected followed by the middle finger which was consistent with the findings of Blumberg and Baumgartner whereas most studies found the thumb to be the most commonly involved digit [14, $15,16,17,18,19]$. In these studies, the order of involvement of the remaining digits varied considerably with the middle finger being second most affected in the study by Park and Joy, while the ring finger was more often affected in the study by Patel $[15,16,19]$. In another study, the middle finger was the most commonly affected digit followed by the ring finger and the thumb ${ }^{[20]}$.

Quinnel has classified Trigger finger into 5 grades based on the severity of symptoms. In our series' most of the patients presented with intermittent locking that was actively correctable which correlates with grade IV of the Quinnel's criteria. No previous study has focused on the importance of the Quinnel's criteria and its role in deciding the treatment modality.

We used an 18 gauge needle which was first described by Eastwood et al., ${ }^{[13]}$. Various other instruments have also been described in the literature for percutaneous release of Trigger finger. Loirthior used a fine tenotome with a blade ${ }^{[21]}$. Tanaka et al., and Joy used a scalpel ${ }^{[16,22]}$. Park et al., utilized a specially designed HAKI knife ${ }^{[15]}$.

There was a success rate of $96 \%$ in our series which was comparable to the reported success rate in literature ranging from $88-100 \%{ }^{[13,15,16,17,18,23,19]}$. Only $4 \%$ patients in our study had residual pain and reduced range of motion which was attributed to incomplete release of the A1 pulley implying a poor result.

The proximity of the Radial digital nerve deters many surgeons to employ this technique. In Carozzella's study, the Radial digital nerve was $2.19 \mathrm{~mm}$ away from the tip of the needle in the thumb and in Pope and Wolfe's study, the nerve was within $2 \mathrm{~mm}$ of the tip of the needle in 3 out 5 thumbs [24, ${ }^{25]}$. The location of the nerve in the other digits have not been specifically mentioned in studies. Various studies including our study have reported no neurological complications $[26,13$, $16,18,20,24,26]$.

Other complications such as bowstring of the tendon have been described in the literature. Heithoff reported bowstring of the flexor tendon in a case report when part of the A2 pulley was also released along with the A1 pulley resulting in severe disability in the form of a painful pulling sensation and the inability to actively extend the digit ${ }^{[27]}$. Proximal pulley reconstruction was required to restore the normal biomechanics of the Metacarpophalyngeal joint which relieved pain and improved range of motion. However none of the patients in our series reported bowstringing of the flexor tendon at 6 months follow up.

We found postoperative pain and stiffness in $11 \%$ cases 
which resolved with analgesics and physiotherapy. Park et al., also reported instances of residual pain and stiffness post procedure ${ }^{[26]}$. This has been attributed to incomplete release of the A1 pulley, laceration of the flexor tendon, postoperative adhesions of the flexor tendon ${ }^{[22]}$.

Percutaneous release requires only a disposable needle however open surgery requires the an operation theatre, sterile instruments, a battery of pre-operative investigations and suture materials which leads us to believe that the percutaneous technique is a less expensive and cost effective method for the management of trigger finger despite not performing a cost analysis study.

\section{Conclusion}

To conclude, we believe that percutaneous release of trigger finger is a simple, safe, reliable and cost effective method which provides immediate relief from symptoms of pain and catching and can be done in the out-patient setting. It is not too dangerous nor is the learning curve so great that it has to be reserved for experienced surgeons. We believe all patients presenting with trigger finger should receive a trial with the percutaneous technique before considering open release.

\section{References}

1. Makkouk AH, Oetgen ME, Swigart CR, Dodds SD. Trigger finger: Etiology, evaluation, and treatment. Curr Rev Musculoskelet Med 2008;1(2):92-96.

2. Sato ES, Gomes Dos Santos JB, Belloti JC, Albertoni WM, Faloppa F. Treatment of trigger finger: Randomized clinical trial comparing the methods of corticosteroid injection, percutaneous release and open surgery. Rheumatology (Oxford) 2012;51:93-99.

3. Drossos K, Remmelink M, Nagy N, de Maertelaer V, Pasteels JL, Schuind F. Correlations between clinical presentations of adult trigger digits and histologic aspects of the A1 pulley. J Hand Surg Am 2009;34(8):14291435.

4. Cederlund RI, Thomsen N, Thrainsdottir S, Eriksson KF, Sundkvist G, Dahlin LB. Hand disorders, hand function, and activities of daily living in elderly men with Type 2 diabetes. J Diabetes Complications 2009;23(1):32-39.

5. Goldfarb C. Green's Operative Hand Surgery. J Bone Joint Surg Am 2005;87(12):2842.

6. Colbourn J, Heath N, Manary S, Pacifico D. Effectiveness of splinting for the treatment of trigger finger. J Hand Ther 2008;21:336-343.

7. Fleisch SB, Spindler KP, Lee DH. Corticosteroid injections in the treatment of trigger finger: A level I and II systematic review. J Am Acad Orthop Surg 2007;15(3):166-171.

8. Slesarenko YA, Mallo G, Hurst LC, Sampson SP, SerraHsu F. Percutaneous release of A1 pulley. Tech Hand Up Extrem Surg 2006;10(1):54-56.

9. Lalonde D, Martin A. Epinephrine in local anesthesia in finger and hand surgery: The case for wide-awake anesthesia. J Am Acad Orthop Surg 2013;21:443-447.

10. Cederlund RI, Thomsen N, Thrainsdottir S, Eriksson KF, Sundkvist G, Dahlin LB. Hand disorders, hand function, and activities of daily living in elderly men with Type 2 diabetes. J Diabetes Complications 2009;23(1):32-39.

11. Saldana MJ. Trigger digits: Diagnosis and treatment. J Am Acad Orthop Surg 2001;9(4):246-252.

12. Sampson SP, Badalamente MA, Hurst LC, Seidman J. Pathobiology of the human A1 pulley in trigger finger. J Hand Surg Am 1991,16(4):714-21.
13. Eastwood DM, Gupta KJ, Johnson DP. Percutaneous release of trigger finger: an office procedure. J Hand Surg 1992;17A:114-117.

14. Baumgarten KM, Gerlach D, Boyer MI. Corticosteroid injection in diabetic patients with trigger finger. A prospective, randomized, controlled double-blinded study. J Bone Joint Surg Am 2007;89(12):2604-11.

15. Park MJ, Oh I, Ha KI. A1 pulley release of locked trigger digit by percutaneous technique. J Hand Surg (British and European volume) 2004;29B:502-505.

16. Joy AK, Brogen AK, Wangjam K, Singh I, Bimol N, Nilachandra L. Percutaneous release of trigger fingers: Is it reserved for few surgeons? IJPMR 13 2002, P1-4.

17. Cebesoy O, Karakurum G, Kose KC, Baltaci ET, Isik M. Percutaneous release of the trigger thumb: Is it safe, cheap and effective? International Orthopaedics (SICOT) 2007;31:345-249.

18. Blumberg N, Arbel R, Dekel S. Percutaneous release of trigger digits. J Hand Surg (British \& European volume) 2001;26(3):256-257.

19. Patel MR, Moradia VJ. Percutaneous release of trigger digit with and without cortisone injection. J Hand Surg 1997;22A:150-5.

20. Cihantimur B, Akin S, Ozcan M. Percutaneous treatment of trigger finger. 34 fingers followed 0.5-2 years. Acta Orthop Scand 1998;69 (2):167-168.

21. Lorthioir J. Surgical treatment of trigger-finger by a subcutaneous method. J Bone Joint Surg 1958;40A:793795.

22. Tanaka M, Muraji M, Negoro H, Yamashita H, Nakano T, Nakano K. Subcutaneous release od trigger thumb and fingers in 210 fingers. J Hand Surg (British and European volume) 1990;15(4):463-465.

23. Maneerit J, Sriworakun C, Budhraja N, Nagavajara P. Trigger thumb: results of prospective randomised study of percutaneous release with steroid injection versus steroid injection alone. J Hand Surg (British \& European volume) 2003;28(6):586-589.

24. Pope DF, Wolfe SW. Safety and efficacy of percutaneous trigger finger release. J Hand Surg 1995;20A:280-283.

25. Carrozzella J, Stern PJ, Von Kuster LC. Transection of radial digital nerve of the thumb during trigger release. $\mathrm{J}$ Hand Surg 1989;14A:198-200.

26. Ha KI, Park MJ, Ha CW. Percutaneous release of trigger digits. A technique and results using specially designed knife. J Bone Joint Surg (Br) 2001;83B:75-77.

27. Heithhoff SJ, Millender LH, Helman J. Bowstringing as a complication of trigger finger release. J Hand Surg 1988;13A:567-70.

28. Newport ML, Lane LB, Stuchin SA. Treatment of trigger finger by steroid injection. Journal of Hand Surgery 1990;15A:748-750. 